\title{
Hydrophobic, mechanical, and tribological properties of fluorine incorporated hydrogenated fullerene-like carbon films
}

\author{
Li QIANG, Bin ZHANG, Kaixiong GAO, Zhenbin GONG, Junyan ZHANG* \\ State Key Laboratory of Solid Lubrication, Lanzhou Institute of Chemical Physics, Chinese Academy of Sciences, Lanzhou 730000, China \\ Received: 20 June 2013 / Revised: 07 September 2013 / Accepted: 25 October 2013 \\ (C) The author(s) 2013. This article is published with open access at Springerlink.com
}

\begin{abstract}
Fluorine-incorporated hydrogenated fullerene-like nanostructure amorphous carbon films (F-FLC) were synthesized by employing the direct current plasma enhanced chemical vapor deposition (dc-PECVD) technique using a mixture of methane $\left(\mathrm{CH}_{4}\right)$, tetra-fluoromethane $\left(\mathrm{CF}_{4}\right)$, and hydrogen $\left(\mathrm{H}_{2}\right)$ as the working gases. The effect of the fluorine content on the bonding structure, surface roughness, hydrophobic, mechanical, and tribological properties of the films was systematically investigated using Fourier transform infrared spectroscopy (FTIR), X-ray photoelectron spectroscopy (XPS), Raman analysis, atomic force microscope (AFM), contact angle goniometer, nano-indenter, and reciprocating ball-on-disc tester, respectively. The fluorine content in the films increased from 0 to 2.1 at. $\%$ as the $\mathrm{CF}_{4}$ gas flow ratio increased from 0 to $3 \mathrm{sccm}$, and incorporated fluorine atoms existed in the form of $C-\mathrm{F}_{X}(X=1,2,3)$ bonds in the film. The fullerene nanostructure embedded in the hydrogenated amorphous carbon films was confirmed by Raman analysis. The water contact angle was significantly increased because of fluorine doping, which indicates that the hydrophobicity of the carbon films could be adjusted to some extent by the fluorine doping. The hardness and elastic modulus of the films remained relatively high $(22 \mathrm{GPa}$ ) as the fluorine content increased. Furthermore, the friction coefficient of the carbon films was significantly reduced and the wear resistance was enhanced by fluorine doping.
\end{abstract}

Keywords: fullerene-like carbon film; fluorine doping; hydrophobicity; mechanical properties; tribological performance

\section{Introduction}

Hydrogenated diamond-like carbon (DLC) films have attracted significant interest in the area of science because of their extraordinary properties such as high mechanical hardness, low friction coefficient, and high wear resistance [1-4]. These properties make them excellent candidates for a wide range of applications. Generally, the mechanical properties are mainly determined by the $\mathrm{sp}^{3}$ hybrid carbon content, which contributes to higher mechanical hardness. It should be noted that our previous studies have reported films with a hardness of $20.9 \mathrm{GPa}$ and elastic recovery as high as $84 \%$, and these excellent properties were

\footnotetext{
* Corresponding author: Junyan ZHANG.

E-mail: zhangjunyan@licp.cas.cn
}

attributed to the unique fullerene-like nanostructure embedded in the amorphous diamond-like carbon matrix $[5,6]$. However, fullerene-like nanostructure carbon (FLC) films with high $\mathrm{sp}^{2}$ hybrid carbon content showed excellent mechanical properties. This is due mainly to the presence of the curvature in an all-sp² three-dimensional network, as with a "molecule spring" fixed in the amorphous carbon matrix $[7,8]$. This also indicates that the $\mathrm{sp}^{3}$ hybrid carbon content is not the only factor that determines the mechanical properties of the film, as the microstructure also significantly affects the mechanical properties.

From the above discussion, fullerene-like nanostructure carbon films have promising and valuable prospect as protective coating. Furthermore, it is well known that the incorporation of non-metallic elements, including N [9], Si [10, 11], and F [12-14], can 
significantly improve and modify the performances of films. Among them, fluorine incorporated DLC films have attracted significant interest due to their superior low friction coefficient, low surface energy, low internal stress, particularly excellent biocompatibility, and hydrophobic properties. Yu et al. [15] found that the $\mathrm{F}$ content rapidly increased with the introduction of $\mathrm{CF}_{4}$, leading to a sharp reduction in the surface energy of the film. Marciano [16] also reported that F-DLC films presented lower stress and surface free energy as their F content increased. In addition, according to Refs. $[17,18]$, the biocompatibility and hydrophobic properties can be effectively improved by the incorporation of fluorine. Recently, a number of deposition technologies have been proposed for the synthesis of F-FLC films [19-21]; the common deposition technique involves the use of a pulsed direct current plasma enhanced chemical vapor deposition (dc-PECVD) system, which has several advantages such as low film stress, low deposition temperature, and good uniformity on a large-area substrate.

Considering the complexity and diversity of amorphous carbon film, in our present work, we synthesized fluorine-incorporated hydrogenated fullerene-like amorphous carbon films (F-FLC) by employing the pulsed dc-PECVD technique using a mixture of methane $\left(\mathrm{CH}_{4}\right)$, tetra- fluoromethane $\left(\mathrm{CF}_{4}\right)$, and hydrogen $\left(\mathrm{H}_{2}\right)$ gases. The aim of this work is to study the effect of the $\mathrm{F}$ content on the properties of FLC film, and to determine whether the hydrophobic, mechanical, and tribological properties of the FLC film can be significantly improved by fluorine doping.

\section{Experimental details}

\subsection{Film deposition}

All of the films were prepared on a Si substrate (n-100) using the dc-PECVD technique. The substrate was sequentially ultrasonic cleaned in ethanol and acetone for $10 \mathrm{~min}$ to remove surface stains, then dried in the ambient atmosphere and placed into the chamber. Prior to the deposition, the vacuum chamber was evacuated up to $1.0 \times 10^{-3} \mathrm{~Pa}$, and then $300 \mathrm{sccm}$ argon was introduced into the chamber. The entire $\mathrm{Si}$ substrate was first cleaned by argon discharge for 30 min at a discharge voltage of $-800 \mathrm{~V}$. During this time, the working pressure was kept at $4.8 \mathrm{~Pa}$. The working gas of the deposition was composed of $300 \mathrm{sccm}$ Ar, $10 \mathrm{sccm} \mathrm{CH}_{4}$, and $20 \mathrm{sccm} \mathrm{H}_{2}$. The diameters of the upper electrode and the substrate holder were 300 and $200 \mathrm{~mm}$, respectively, and the distance between the two electrodes was $5 \mathrm{~cm}$. A negative pulsed voltage of $1,000 \mathrm{~V}$ and a duty-cycle of $80 \%$ were applied to the substrate, and the working pressure was kept at $15 \mathrm{~Pa}$. The deposition time was set as $120 \mathrm{~min}$. The fluorine content was controlled by varying the $\mathrm{CF}_{4}$ gas flow to $0,1 \mathrm{sccm}, 1.5 \mathrm{sccm}$, and $3 \mathrm{sccm}$. The substrate is not heated, while the temperature was unintentionally increased to around $100^{\circ} \mathrm{C}$ because of the plasma bombardment during the deposition process. After processing, the samples were cooled down inside the chamber.

\subsection{Sample characterization}

The thickness of the films was measured using crosssection scanning electron microscope (SEM) images, and the deposition rate can be obtained by the ratio of the thickness to the deposition time. The bonding structure and the chemical state were characterized using Fourier Transform Infrared Spectroscopy (FTIR) in the range of $400-4,000 \mathrm{~cm}^{-1}$, with a $2 \mathrm{~cm}^{-1}$ resolution and 32 scan times at room temperature. The microstructure of the films was characterized by VG ESCALAB 210 type X-ray photoelectron spectroscopy (XPS), with $\mathrm{Al} \mathrm{K \alpha}$ radiation (photo energy $1476.6 \mathrm{eV}$ ) as the excitation source and using a Raman spectrometer (Jobin Yvon T64000) in back-scattering configuration with laser excitation at a wavelength of $514.5 \mathrm{~nm}$, which is over the $800-2,000 \mathrm{~cm}^{-1}$ wavenumber range. The surface topography was observed by a Smart SPM type atomic force microscope (AFM, AIST-NT Co, USA), and the relative roughness factor (Ra) was calculated by the analysis of a Nanoscope III 5.12r2 program. The hydrophobicity examination of the film was performed using purified water by employing the sessile drop method with a DSA100type (KRUSS Co., Germany) contact angle goniometer, which has an accuracy of $2^{\circ}$. For each sample, 5 different surface location measurements were evaluated to obtain average values, and all measurements were reported as the mean of 5 replicates to obtain more 
reliable data. The hardness and elastic recovery were measured by a nanoindenter (Nano indenter II, MTS. Co., USA) with a maximum indentation depth of $50 \mathrm{~nm}$. The tribological properties were tested using a UMT-2MT ball-on-plate reciprocating tribo-tester, which slides at $25^{\circ} \mathrm{C}$ and at a relative humidity (RH) of $15 \%-19 \%$. As the mating material, $\mathrm{Al}_{2} \mathrm{O}_{3}$ balls $(\phi 5 \mathrm{~mm})$ were ultrasonic cleaned with acetone before each test. All of the measurements were performed at a sliding velocity of $15 \mathrm{~cm} / \mathrm{s}$ and with a $30 \mathrm{~N}$ load. The sliding distance was $90 \mathrm{~m}$. The specific friction coefficient was calculated by averaging the data of at least 5 individual operations. After friction, the wear morphologies of mating balls and scars of the films were observed by SEM. The wear volume was calculated by measuring the wear scars of the substrate with a three-dimensional profilometer, and then the specific wear rates $(k)$ of the films were obtained from Eq. (1) as follows

$$
k=V /(D \cdot L)
$$

where $V$ is the wear volume of the samples, $D$ is the sliding distance, and $L$ is the sliding load.

\section{Results and discussion}

\subsection{Fluorine content, deposition rate, and fluorine atoms bond state}

Figure 1 depicts the dependence of the fluorine content and deposition rate of the films on the $\mathrm{CF}_{4}$ gas flow. It is clear that the fluorine content increases with the increase of the $\mathrm{CF}_{4}$ gas flow (confirmed by XPS). As

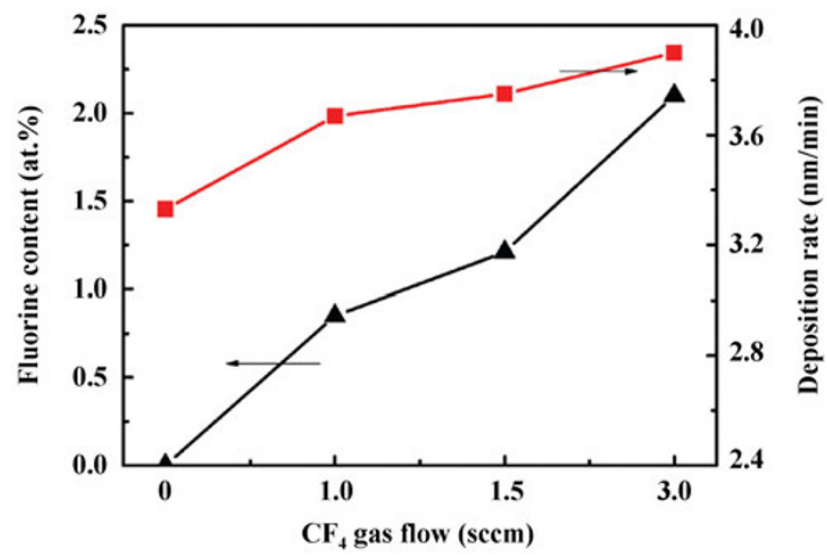

Fig. 1 The dependence of the fluorine content and the deposition rate on the $\mathrm{CF}_{4}$ gas flow. the $\mathrm{CF}_{4}$ gas flow increases from 0 to $1 \mathrm{sccm}$, the fluorine content increases from 0 (FLC) to 0.85 at.\% (F-FLC1). As the $\mathrm{CF}_{4}$ gas flow increases further, the fluorine content increases from 1.21 at.\% (F-FLC2) to 2.1 at.\% (F-FLC3). The result implies that the fluorine content can be adjusted by varying the $\mathrm{CF}_{4}$ gas flow, which is consistent with the results of many studies [22-24]. Furthermore, the deposition rate of the films still increased slightly from $3.3 \mathrm{~nm} / \mathrm{min}$ to $3.9 \mathrm{~nm} / \mathrm{min}$ as the $\mathrm{CF}_{4}$ gas flow increased from 0 to $3 \mathrm{sccm}$.

Figure 2(a) shows the FTIR spectrum of the films. The $\mathrm{C}-\mathrm{F}$ vibrational modes for the wavenumber range of $400-2,200 \mathrm{~cm}^{-1}$ are listed in Table $1[25,26]$. The broad peak at 2,950 $\mathrm{cm}^{-1}$ for the $\mathrm{CH}_{n}$ group and the bond at $1,600 \mathrm{~cm}^{-1}$ of $\mathrm{C}=\mathrm{C}$ stretching are so weak that it is not easily found. This indicates that there is little hydrogen in the films. Besides, the FTIR spectrum can be divided into two groups: the absorption peak located at $600 \mathrm{~cm}^{-1}$, which is associated with the $\mathrm{CF}_{2}$ wagging mode (Group I), and a broad bond observed in the range of $980-1,500 \mathrm{~cm}^{-1}$ (Group II). The peak
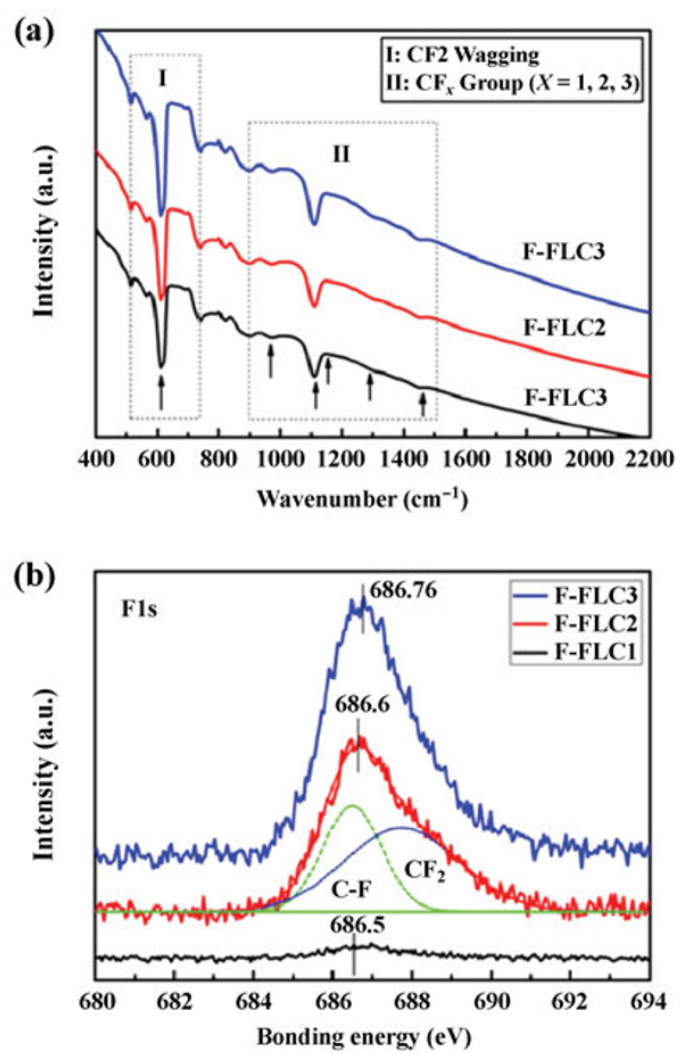

Fig. 2 (a) the FTIR spectrum and (b) the XPS F1s peak of the film as a function of the fluorine content. 
Table 1 FTIR assignment for different vibrational modes of F-DLC films.

\begin{tabular}{ccl}
\hline Group & Wavenumber $\left(\mathrm{cm}^{-1}\right)$ & \multicolumn{1}{c}{ Vibrational modes } \\
\hline I & 650 & $\mathrm{CF}_{2}$ wagging \\
II & 980 & $\mathrm{CF}_{3}$ \\
& 1030 & $\mathrm{CF}$ \\
& 1050 & $\mathrm{CF}$ in $\mathrm{CF}_{2}$ \\
& 1160 & $\mathrm{CF}_{2}$ symmetric stretch \\
& 1220 & $\mathrm{CF}_{2}$ asymmetric stretch \\
& 1340 & $\mathrm{CF}_{\text {stretch }}$ \\
& 1450 & $\mathrm{CF}_{2}$ asymmetric stretching \\
\hline
\end{tabular}

near $1,000 \mathrm{~cm}^{-1}$ is attributed to the $\mathrm{C}-\mathrm{F}$ bond and the sharp peak at $1,100 \mathrm{~cm}^{-1}$ is due to $\mathrm{CF}_{2}$. Moreover, the XPS F 1s spectra of the films with different fluorine contents are shown in Fig. 2(b). The intensity of the F 1s peak clearly increased and the peak position shifted slightly toward a higher binding energy with an increase in the fluorine content from $686.5 \mathrm{eV}$ for the F-FLC1 film to 686.6 and $686.8 \mathrm{eV}$ for the F-FLC2 and F-FLC3 films, respectively. The F1s spectra could be divided by the Gaussian fitting into two peaks, centered at $686.4 \mathrm{eV}$ and $687.8 \mathrm{eV}$, related to the $\mathrm{C}-\mathrm{F}$ and $\mathrm{C}-\mathrm{F}_{2}$ bonding, respectively. The higher $\mathrm{F}$ content in the film clearly leads to a higher $\mathrm{C}-\mathrm{F}_{2}$ content, resulting in a higher binding energy shift. The results from the FTIR and XPS F1s analysis suggested that the incorporated fluorine atoms exist mainly in the form of the $\mathrm{C}-\mathrm{F}, \mathrm{C}-\mathrm{F}_{2}$, and $\mathrm{C}-\mathrm{F}_{3}$ bonds in the film.

\subsection{Raman analysis}

Raman spectroscopy, which is a popular, effective, and non-destructive tool that is used to distinguish different bonding types, was used to probe the bonding structure of the carbon films. Figure 3 displays the Raman spectra of the conventional amorphous carbon film and the FLC films. A broad asymmetric Raman bond, which represents the typical features of the conventional DLC films, could be observed in the wavenumber range of $800-2,000 \mathrm{~cm}^{-1}$ (Fig. 3(a)). Normally, the Raman spectrum can be fitted into two Gaussian peaks: (1) a relatively sharp peak (so-called $\mathrm{G}$ peak), which originated from all pairs of $\mathrm{sp}^{2}-\mathrm{C}$ atoms in both rings and chains, is located at about $1,580 \mathrm{~cm}^{-1}$, and (2) a shoulder peak (D bond), which is assigned to the breathing mode of $\mathrm{sp}^{2}-\mathrm{C}$ atoms
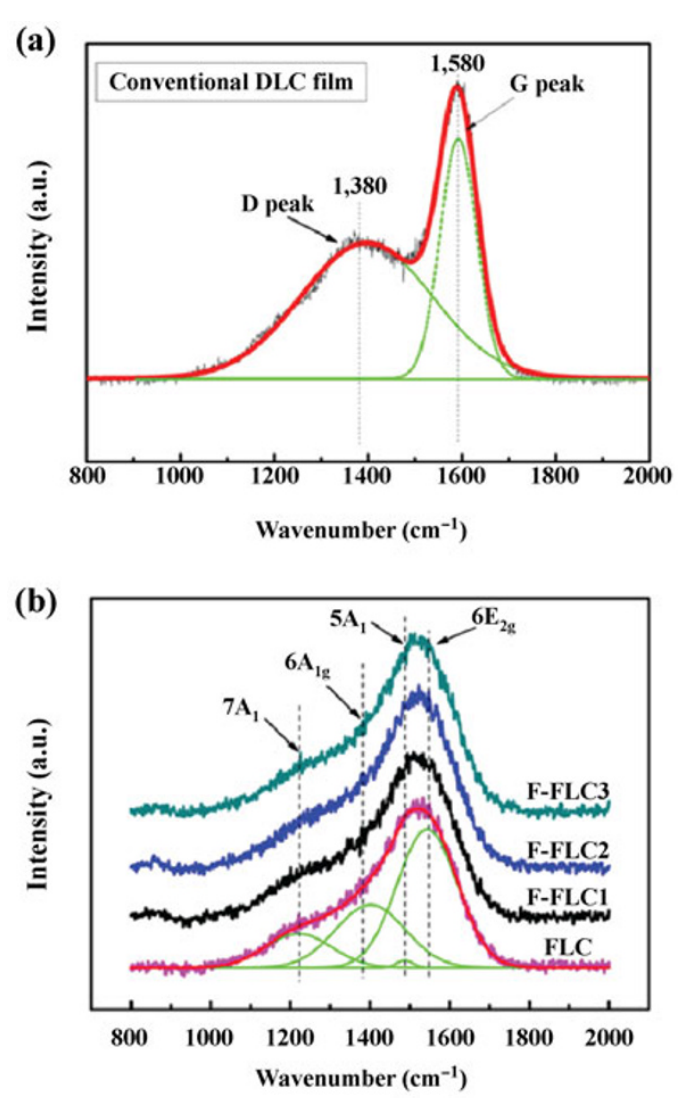

Fig. 3 The Raman spectra of (a) the convention DLC film and (b) the FLC films.

only in aromatic rings, appeared at approximately $1,380 \mathrm{~cm}^{-1}$ [27]. However, in addition to the D and G peaks, two additional Gaussian peaks centered at approximately $1,230 \mathrm{~cm}^{-1}$ and $1,490 \mathrm{~cm}^{-1}$ were also observed, as shown in Fig. 3(b), which is consistent with our previous results $[5,28]$ that indicated that these two peaks originated from the seven- and fivenumber carbon rings of curved graphite, fullerene, or onion.

\subsection{Surface roughness and hydrophobicity}

The relative roughness factor $(\mathrm{Ra})$ roughness of the film surface was obtained using the smart SPM-type AFM technique, as shown in Fig. 4. Table 2 summarizes the specific Ra values as a function of the fluorine content. For a fluorine content of 0 , the film has a flat and smooth surface and the Ra value is $0.37 \mathrm{~nm}$. When the fluorine content increased up to 2.1 at.\%, the surface of the film becomes rougher and many protuberances appear, and the Ra value also increases significantly from $0.37 \mathrm{~nm}$ to $1.07 \mathrm{~nm}$. The effects of the 

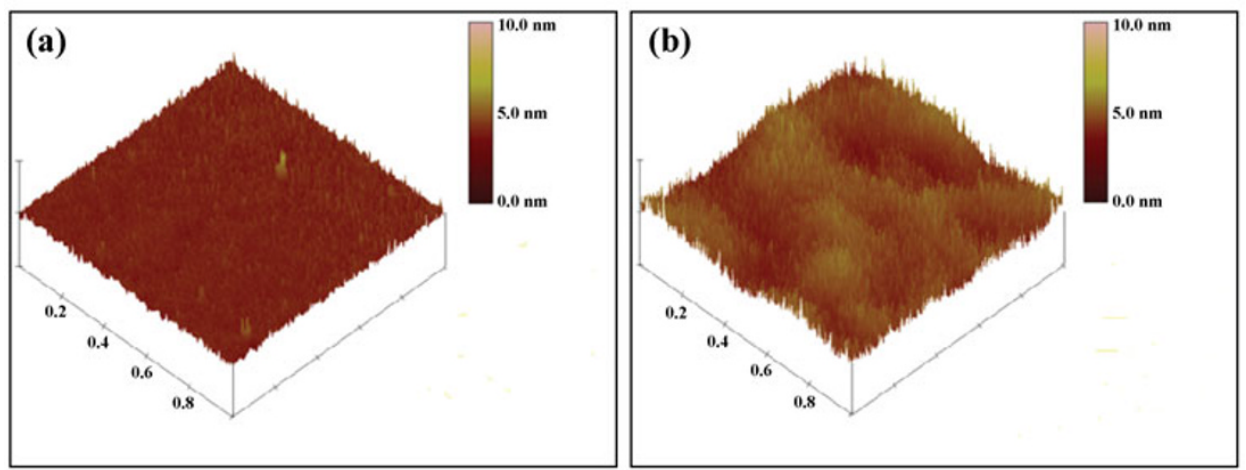

Fig. 4 AFM images of the film with a fluorine content of (a) 0 and (b) 2.1 at.\%.

Table 2 The surface roughness ( $\mathrm{Ra}$ ) of the films as a function of the fluorine content.

\begin{tabular}{cc}
\hline Samples & Ra roughness $(\mathrm{nm})$ \\
\hline FLC & 0.37 \\
F-FLC $(\mathrm{F}=0.85$ at.\%) & 0.59 \\
F-FLC (F = 1.21 at.\%) & 0.72 \\
F-FLC (F = 2.10 at.\%) & 1.07 \\
\hline
\end{tabular}

ions' bombardment may contribute to the increased surface roughness [29]. With the increase of the fluorine content, an increasing number of $\mathrm{F}^{+}$ions bombarded the film surface, which would promote increased surface roughness.

The hydrophobicity of the films was determined by the water contact angle. Figure 5 shows the variation of the water contact angles as a function of the fluorine content. Clearly, the water contact angle continuously increases with the fluorine content. The water contact
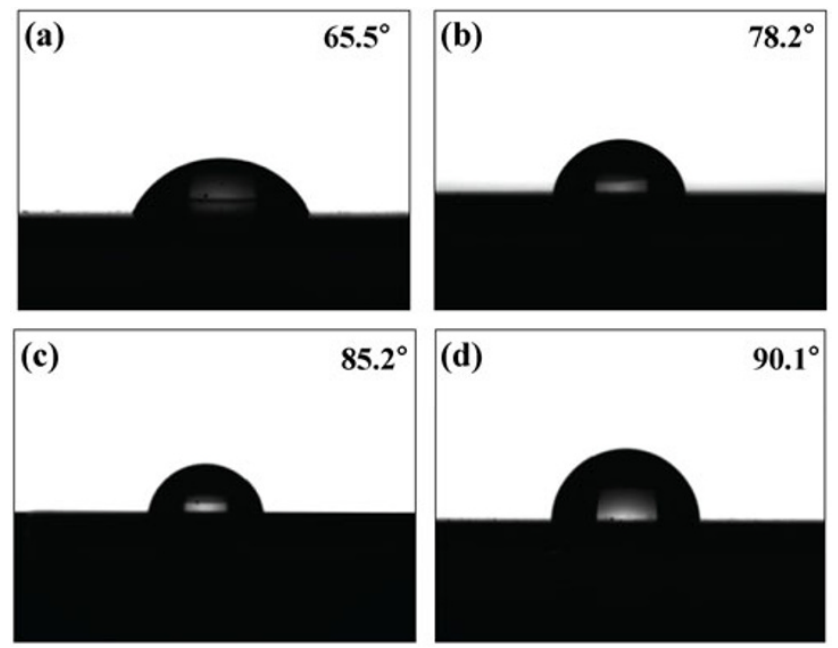

Fig. 5 Water contact angles for the film with a fluorine content of (a) 0 , (b) 0.85 at.\%, (c) 1.21 at.\%, and (d) 2.1 at.\%. angle is $65.5^{\circ}$ for the FLC film, and quickly increases to $78.2^{\circ}$ for the F-FLC1 film. Eventually, the water contact angle reaches $90.1^{\circ}$ for the F-FLC3 film. This suggests that the increase in the water contact angle is due mainly to the incorporation of $\mathrm{F}$, which is consistent with Ref. [30]. It is clear that the increase in the water contact angle is due not only to the presence of $\mathrm{CFx}_{\mathrm{x}}$ bonds, but also to the surface roughness. Previous studies $[31,32]$ have shown that the surface roughness can significantly affect the hydrophobicity of the films, as a smoother surface will result in a smaller water contact angle. As the fluorine content increases, the surface roughness increases, as shown in Table 2, leading to the increased water contact angle.

\subsection{Mechanical and tribological properties}

Figure 6 illustrates the hardness and elastic modulus of the films as a function of the fluorine content. The lowest hardness of about $21.2 \mathrm{GPa}$ and elastic modulus of around $179 \mathrm{GPa}$ were observed for the FLC film. As the fluorine content increases, the hardness and elastic modulus increase to $22.6 \mathrm{GPa}$ and $184.1 \mathrm{GPa}$ for the F-FLC1 film, respectively. Ultimately, for the F-FLC3 film, the hardness and elastic modulus increase to $23.1 \mathrm{GPa}$ and $191 \mathrm{GPa}$, respectively. Generally, the hardness and elastic modulus of the film will decrease due to the fluorine doping, which, because it is a termination radical, could disrupt the continuity of the $\mathrm{C}-\mathrm{C}$ network [33]. However, in this study, the hardness and elastic modulus monotonously increase with the increasing fluorine content. The bombardment effect of the $\mathrm{F}^{+}$ions should be considered because the $\mathrm{F}^{+}$ions bombardment results in not only an increase in the film density, but also the increase of compressive 


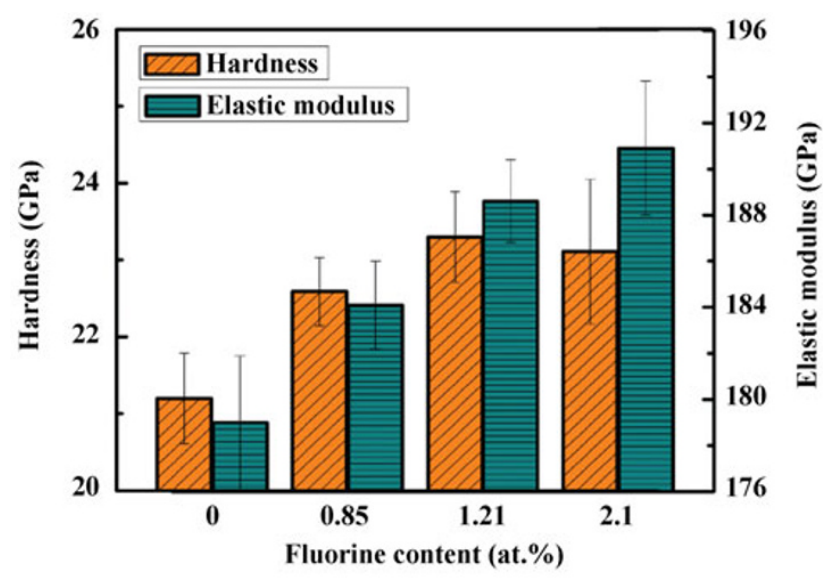

Fig. 6 The elastic modulus and hardness of the F-FLC films as a function of the fluorine content.

stress in the film. The increased hardness and elastic modulus may be due to a combination of the increases in both the density and the compressive stress.

The friction and wear property of the films were measured on the reciprocating ball-on-disc tester. The friction coefficient curves of the films as a function of the fluorine content are shown in Fig. 7(a), and the steady state friction coefficients are also given in Fig. 7(b). It can be observed that the FLC film presents a high friction coefficient of around 0.029 . When the fluorine content increases to 0.85 at. $\%$, the friction coefficient sharply decreases to 0.019 . When the fluorine content then increases to 2.1 at.\%, the lowest friction coefficient of about 0.011 was obtained. Figure 8 shows the wear surface and the corresponding wear scar of the matching ball. There is some obvious wear debris scattered on both sides of the wear track for the FLC film, while no obvious wear was found, as shown in Fig. 8(b). Moreover, the corresponding wear scar of the matching ball for the FLC film is also obviously larger than that of the F-FLC3 film (2.1 at.\%), which implies that the F-FLC film possesses more excellent wear resistance compared with the FLC film. The specific wear rate of the F-FLC3 film is $5.3 \times 10^{-9} \mathrm{~mm}^{3} / \mathrm{Nm}$, much lower than that of the FLC film, which is around $15 \times 10^{-9} \mathrm{~mm}^{3} / \mathrm{Nm}$. There is usually a close relationship between the tribological and mechanical properties, and the outstanding wear resistance of the F-FLC3 film may be attributed to its higher hardness and elastic modulus. This result indicates that a much better wear resistance could be obtained by fluorine doping.
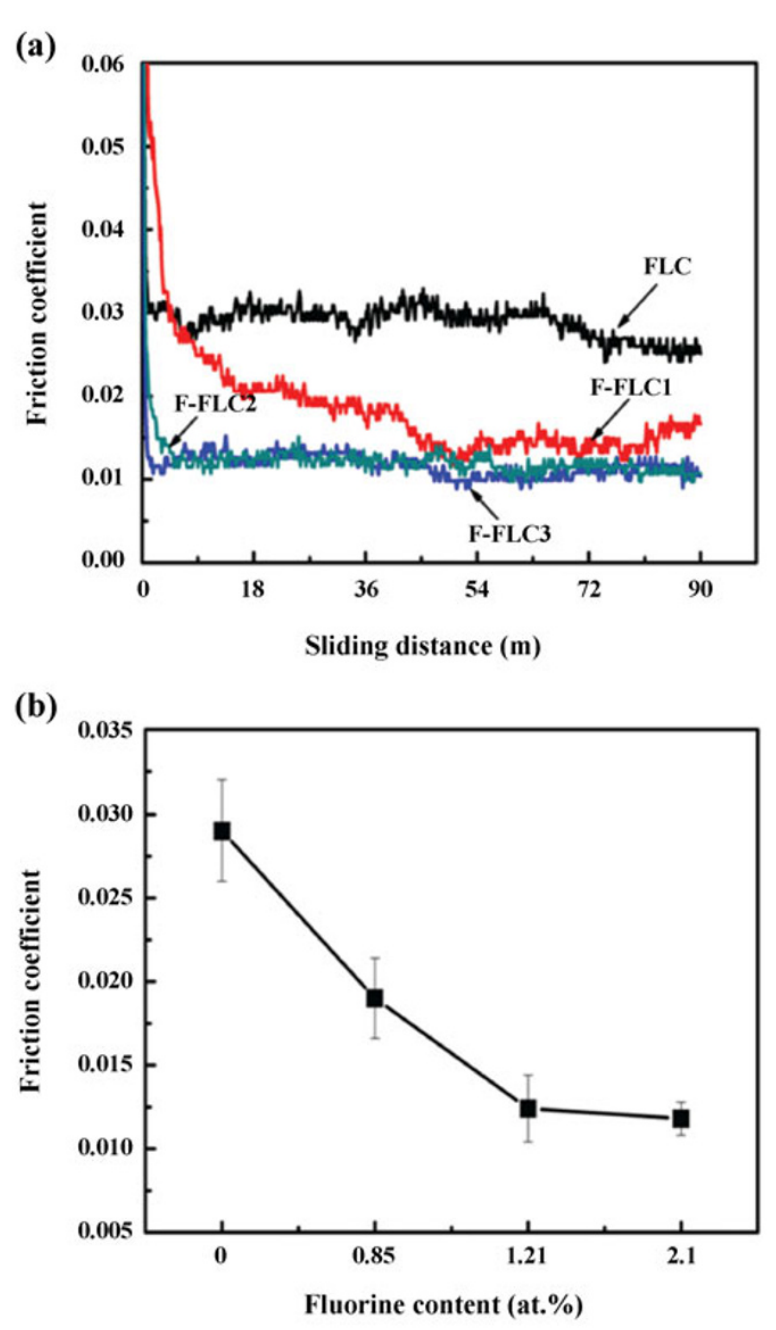

Fig. 7 Friction coefficient of the F-FLC films as a function of the fluorine content.
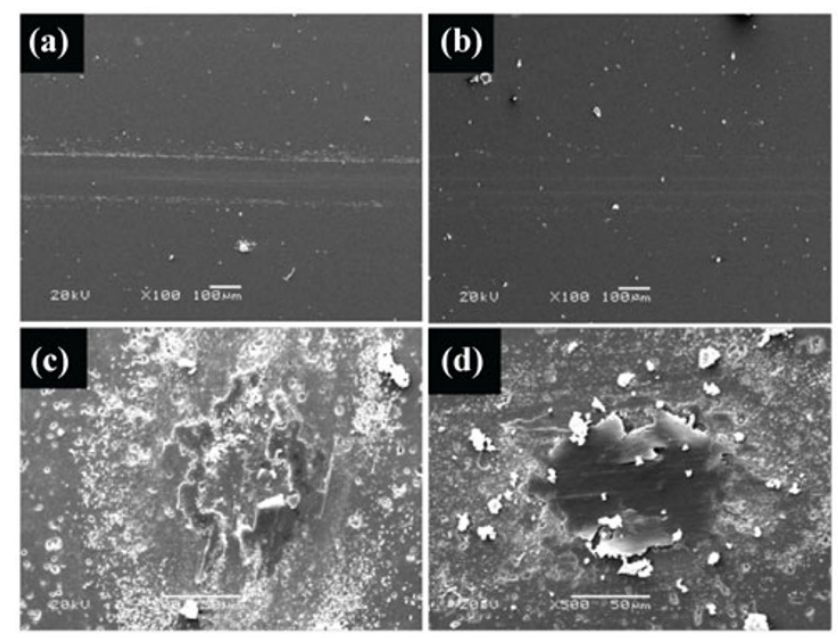

Fig. 8 Wear surface of the films with the fluorine content of (a) 0 and (b) 2.1 at.\% and the corresponding wear scar (c) and (d) of the contact balls. 


\section{Conclusions}

Fluorine incorporated hydrogenated fullerene-like nanostructure carbon films were deposited on the $\mathrm{Si}$ wafer using the dc-PECVD technique. The fluorine content increased from 0 to 2.1 at. $\%$ as the $\mathrm{CF}_{4}$ gas flow increased from 0 to $3 \mathrm{sccm}$. The influence of the fluorine content on the bonding structure, hydrophobicity, and mechanical and tribological properties of the films were investigated systematically. Both the fluorine content and deposition rate increased with the increase of the $\mathrm{CF}_{4}$ gas flow. The FTIR and XPS analyses indicated that the incorporated fluorine atoms exist in the form of $C-\mathrm{F}_{X}(X=1,2,3)$. Raman spectroscopy showed that the fullerene nanostructure has been successfully embedded in the amorphous carbon film. The AFM images suggested that the surface roughness increased with the increase of the fluorine content, which may be due to the bombardment of the $\mathrm{F}^{+}$ions. As a result, the hydrophobicity, which is assessed using the water contact angles, has been effectively improved. However, the hardness and elastic modulus were not reduced, but with an increase tendency although the degree of the increase is very small, which may be attributed to the slight increases in the film density and the compressive stress induced by the $\mathrm{F}^{+}$ion bombardment. In addition, the lower friction coefficient and outstanding wear resistance could also be obtained by fluorine doping, which is mainly due to the excellent mechanical properties.

\section{Acknowledgements}

The authors are grateful to the National Key Basic Research and Development (973) Program of China (Grant No. 2013CB632300) and the National Natural Science Foundation of China (Grant Nos. 51275508 and 51205383) and the Ministry of Science and Technology of China (Grant No. 2010DFA63610) for financial support.

Open Access: This article is distributed under the terms of the Creative Commons Attribution License which permits any use, distribution, and reproduction in any medium, provided the original author(s) and source are credited.

\section{References}

[1] Cho G, Yen B K, Klug C A. Structural characterization of sputtered hydrogenated amorphous carbon films by solid state nuclear magnetic resonance. J Appl Phys 104: 013531 (2008)

[2] Qiang L, Zhang B, Zhou Y, Zhang J Y. Improving the internal stress and wear resistance of DLC film by low content Ti doping. Solid State Sci 20: 17-22 (2013)

[3] Zhao F, Li H X, Ji L, Wang Y J, Zhou H D, Chen J M. Ti-DLC films with superior friction performance. Diam Relat Mater 19: 342-349 (2010)

[4] Wang A Y, Lee K R, Ahn J P, Han J H. Structure and mechanical properties of $\mathrm{W}$ incorporated diamond-like carbon films prepared by a hybrid ion beam deposition technique. Carbon 44: 1826-1832 (2006)

[5] Wang Q, Wang C B, Wang Z, Zhang J Y. Fullerene nanostructure-induced excellent mechanical properties in hydrogenated amorphous carbon. Appl Phys Lett 91: 141902 (2007)

[6] Wang Z, Wang C B, Zhang B, Zhang J Y. Ultralow friction behaviors of hydrogenated fullerene-like carbon films: Effect of normal load and surface tribochemistry. Tribol Lett 41: 607-615 (2008)

[7] Gago R, Jim'enez I, Neidhardt J, Abendroth B, Caertti I, Hultman L. Correlation between bonding structure and microstructure in fullerene-like carbon nitride thin films. Phys Rev B 71: 125414-125416 (2005)

[8] Wang X, Wang P, Mu B, Yang S R, Zhang J Y. Effects of $\mathrm{Ar} / \mathrm{H} / \mathrm{N}$-ion bombardment on the surface free energy and friction behavior of the fullerene-like hydrogenated carbon (FL-C:H) film. Surf Interface Anal 40: 1475-1480 (2008)

[9] Srinivasan S, Tang Y, Li Y S, Yang Q, Hirose A. Ion beam deposition of DLC and nitrogen doped DLC thin films for enhanced haemocompatibility on PTFE. Appl Surf Sci 258: 8094-8099 (2012)

[10] Lubwama M, McDonnell K A, Kirabira J B, Sebbit A, Sayers K, Dowling D, Corcoran B. Characteristics and tribological performance of DLC and Si-DLC films deposited on nitrilerubber. Surf Coat Tech 206: 4585-4593 (2012)

[11] Hatada R, Flege S, Baba K, Ensinger W, Kleebe H J, Sethmann I. Temperature dependent properties of silicon containing diamond like carbon films prepared by plasma source ion implantation. $J$ Appl Phys 107: 083307-083307-6 (2010)

[12] Bendavid A, Martin P J, Randeniya L, Amin M S. The properties of fluorine containing diamond-like carbon films prepared by plasma-enhanced chemical vapor deposition. Diamond \& Related Materials 18: 66-71 (2009) 
[13] Kanda K, Yamada N, Yokota K, Tagawa M, Niibe M, Okada M, Haruyama Y, Matsui S. Fabrication of fluorine-terminated diamond-like carbon thin film using a hyperthermal atomic fluorine beam. Diam Relat Mater 20: 703-706 (2011)

[14] Bendavid A, Martin P J, Randeniya L, Amin M S, Rohanizadeh R. The properties of fluorine-containing diamond-like carbon films prepared by pulsed DC plasmaactivated chemical vapour deposition. Diam Relat Mater 19: 1466-1471 (2010)

[15] Yu G Q, Tay B K, Sun Z. Fluorinated amorphous diamondlike carbon films deposited by plasma-enhanced chemical vapor deposition. Surf Coat Tech 191: 236-241 (2005)

[16] Marciano F R, Lima-Oliveira D A, Da-Silva N S, Corat E J, Trava-Airoldi V J. Antibacterial activity of fluorinated diamond-like carbon films produced by PECVD. Surf Coat Tech 204: 2986-2990 (2010)

[17] Yao Z Q, Yang P, Huang N, Sun H, Wang J. Structural, mechanical and hydrophobic properties of fluorine-doped diamond-like carbon films synthesized by plasma immersion ion implantation and deposition (PIII-D). Appl Surf Sci 230: 172-178 (2004)

[18] Ahmed M H, Byrne J A, McLaughlin J. Evaluation of glycine adsorption on diamond like carbon (DLC) and fluorinated DLC deposited by plasma-enhanced chemical vapor deposition (PECVD). Surf Coat Tech 209: 8-14 (2012)

[19] Buijnsters J G, Camero M, Vázquez L, Agulló-Rueda F, Gago R, Jiménez I, Gómez-Aleixandre C, Albella J M. Tribological study of hydrogenated amorphous carbon films with tailored microstructure and composition produced by bias-enhanced plasma chemical vapour deposition. Diam Relat Mater 19:1093-1102 (2010)

[20] Wang P, Wang X, Liu W M, Zhang J Y. Growth and structure of hydrogenated carbon films containing fullerene-like structure. J Phys D: Appl Phys 41: 085401 (2008)

[21] Xiong Z W, Jiang F, Chen X R. Structural and optical properties of fullerene-like amorphous carbon with embedded dual-metal nanoparticles. J Alloy Compd 574: 13-17 (2013)

[22] Valentini L, Braca E, Kenny J M, Lozzi L, Santucci S. Relationship between the optical and mechanical properties of fluorinated amorphous carbon thin films. J Non-cryst Solids 291: 153-159 (2001)

[23] Chou C C, Wu Y Y, Lee J W, Yeh C H, Huang J C. Characterization and haemocompatibility of fluorinated DLC and Si interlayer on Ti6A14V. Surf Coat Tech 231: 418-422 (2013)

[24] Rubio-Roy M, Bertran E, Pascual E, Polo M C, Andújar J L. Fluorinated DLC deposited by pulsed-DC plasma for antisticking surface applications. Diam Relat Mater 17: 1728-1732 (2008)

[25] Bottani C E, Lamperti A, Nobili L, Ossi P M. Structure and mechanical properties of PACVD fluorinated amorphous carbon films. Thin Solid Films 433: 149-154 (2003)

[26] Oh T, Choi C K, Lee K M. Investigation of a-C:F films as hydrogenated diamond-like carbon and low- $k$ materials. Thin Solid Films 475: 109-112 (2005)

[27] Robertson J. Diamond-like amorphous carbon. Mater Sci Eng R Rep 37: 129-281 (2002)

[28] Wang C B, Yang S R, Li H X, Zhang J Y. Elastic properties of a-C:N:H films. J Appl Phys 101: 013501 (2007)

[29] Dai W, Zheng H, Wu G S, Wang A Y. Effect of bias voltage on growth property of Cr-DLC film prepared by linear ion beam deposition technique. Vacuum 85: 231-235 (2010)

[30] Ishihara M, Suzuki M, Watanabe T, Nakamura T, Tanaka A, Koga Y. Synthesis and characterization of fluorinated amorphous carbon films by reactive magnetron sputtering. Diam Relat Mater 14: 989-993 (2005)

[31] Koshel D, Ji H, Terreault B, Cote A, Ross G G, Abel G, Bolduc M. Characterization of $\mathrm{CF}_{x}$ films plasma chemically deposited from $\mathrm{C}_{3} \mathrm{~F}_{8} / \mathrm{C}_{2} \mathrm{H}_{2}$ precursors. Surf Coat Tech 173: 161-171 (2003)

[32] Neumann A W. Contact angles and their temperature dependence: Thermodynamic status, measurement, interpretation and application. Adv Colloid Interface Sci 4: 105-191 (1974)

[33] FreireJr F L, Maia da Costa M E H, Jacobsohn L G, Franceschini D F. Film growth and relationship between microstructure and mechanical properties of a-C:H:F films deposited by PECVD. Diam Relat Mater 10: 125-131 (2001) 


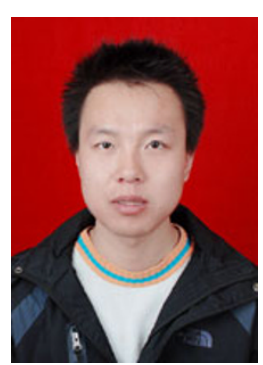

Li QIANG. He received his Bachelor degree in chemistry in 1999 from Northwest University for Nationalities, Lanzhou, China, and MS in chemical engineering in 2012 from

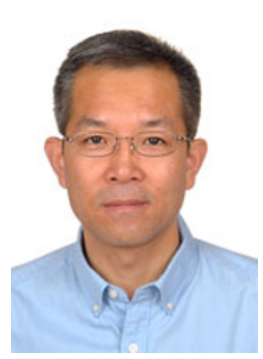

Junyan ZHANG. He received his Bachelor degree in chemistry in 1990 from Lanzhou University, MS in 1997 and $\mathrm{PhD}$ in physical chemistry in 1999, both from Lanzhou institute of Chemical Physics, Chinese Academy of Sciences. He then did his postdoctoral researches at the
Lanzhou University of Technology. Then, he joined Lanzhou Institute of Chemical Physics, Chinese Academy of Sciences. His research interests include carbon thin film as solid lubricant and the application in engine.

University of California at Berkeley, the University of Alabama, and Rice University from 2000 to 2005. In 2007, he spent 3 months in Argonne National Lab as a guest scientist. He is now a professor of Lanzhou Institute of Chemical Physics, Chinese Academy of Sciences. His current research concerns nanostructured carbon films as solid lubrication films and super low friction behaviors and mechanisms. 